\title{
A Strategic Framework for Devolving Responsibility and Functions from Government to the Private Sector
}

\begin{abstract}
Whether a function should be performed within or outside government is a very broad issue that relates to personal values and views concerning the relationship between individual and state, as well as a complex set of management issues. Without trying to answer those questions here, this article begins from the premise that a particular function has been judged by the political process to be the responsibility of government. The article seeks to develop an approach for government managers to use when deciding whether to perform the function directly in-house or to perform the function indirectly through the use of a non-governmental organization. The first part of this article begins by delineating distinguishing characteristics of government, nonprofit, and private organizations, and then assesses the degree to which those characteristics impede or facilitate the performance of public functions. The article then develops a framework and a method for making privatization decisions. The decision to privatize requires strategic thinking; this article provides an example of how a strategic framework might be applied by analyzing the issues that would be faced in privatizing a key element of New York City's homeless program.
\end{abstract}

A new element has found its way into government decision making in the United States as public officials are asked to justify government funding of services and direct government provision of services. Whether a job belongs within or outside government is a very broad policy issue that relates to personal values and views concerning the relationship between the individual and the state. Without trying to answer that question here, this article begins from the premise that a particular function has been judged by the political process to be the responsibility of government. The article seeks to develop an approach for deciding how the function should be carried out-directly by government, or indirectly through the use of a non-governmental organization.

This is a decision that government managers must make every day. The first part of this article examines what might be termed the "functional-matching" approach to privatization. It begins by delineating the distinguishing characteristics of government, nonprofit, and private organizations, and then assesses the degree to which those characteristics impede or facilitate the performance of a carefully defined set of typical public functions. The sec- ond portion of this article seeks to put the theory into practice by beginning the process of developing a framework and a method for making such decisions. The functional-matching process outlined here requires strategic thinking. It is not a straightforward, formulaic set of tasks: It requires decision makers to ask a number of critical questions and then to use their judgment and experience in framing a decision.

\section{Approaches to Privatization}

The modern impulse toward privatization is motivated by various perceived problems that it seeks to solve. The first is the supposed inefficiency of public enterprises due

Steven Cohen is the director of the executive MPA program and the graduate program in Earth Systems, Science, Policy, and Management at Columbia University's School of International and Public Affairs. He is the author of The Effective Public Manager (1998) and the co-author of Environmental Regulation Through Strategic Planning (1991), Total Quality Management in Government (1993), The New Effective Public Manager (1995), Tools for Innovators: Creative Strategies for Managing Public Sector Organizations (1998), and numerous articles on public management innovation, public ethics, and environmental management. Email: sc32@columbia.edu. 
to the absence of the profit motive. The resources obtained by managers in the government sector may not be related to the revenues they generate, but to the importance of the service they deliver. The justification of costs is more important than the potential for revenues. In the private sector, operating resources and capital investments tend to be based on the potential for payout. By removing the relationship of revenues to expenditures, it is difficult to impose a downward pressure on costs, and therefore efficiency is not always rewarded. The second is the problem of over-formality - too many rules governing hiring, purchasing, budgeting, and the scope of activities that may be undertaken by an organization. The third is political influence in the process of managing activities. A fourth problem, more common outside the United States, is state ownership and financial losses from enterprises that do not perform traditional governmental functions (airlines, steel mills, shipyards, railroads, auto factories, phone companies, etc.).

Most scholars of public administration assert that efficiency, organizational informality, and apolitical management are not the only values that organizations should be designed to pursue. Taken to extremes, efficiency, informality, and depoliticization of management would be opposed by advocates of privatization as well. Consider the following extreme examples:

- Efficient law enforcement might execute presumed murderers on the spot to save the costs of legal processes and incarceration.

- An organization without rules and structure would probably not have an accounting system and might simply disperse funds from a big box of cash in a drawer. They might hire staff and promote them on the basis of race or gender.

- An organization implementing a program without political concerns would feel no pressure to be accountable for decisions and might be free to use impoverished elementary school children as a labor force.

In a complex, interconnected society and economy there are, in fact, no purely private organizations. All firms are regulated and must be sensitive to legal, social, cultural, and political constraints. Most private firms pay considerable attention to their public image and customer relations. Conversely, government organizations are not immune to considerations of efficiency. Local governments are quite sensitive to the limits of their tax base and to the need to keep costs as low as possible. Therefore, we are not dealing with differences of kind, but of degree. How regulated is the organization? To what degree does the organization's culture and management promote cost consciousness? To what degree is the organization sensitive to its public image, and how much does it worry about political support and opposition?
Government leaders who are designing and implementing public programs must decide whether to provide government or private organizations with the resources and authority to carry out programs. On what basis should this issue be decided? What framework can decision makers use to make this choice? While there is no simple answer, a number of public management scholars have addressed this issue. In The Privatization Decision, John D. Donahue states, "The choice between public and private has two basic dimensions. The first dimension concerns financing: Should we pay for some good or service individually, out of our own resources, or should we pay for it collectively with funds raised through one form or another of taxation? The second dimension concerns performance: Should the good be produced or the service delivered by a governmental organization or a nongovernmental organization?" ( Donahue 1989, 7).

The goal of Donahue's book "is to develop and illustrate a set of principles to guide the allocation of publicly financed tasks between governmental and nongovernmental organizations" (10). To succeed at this task, one faces the difficulty of distinguishing the operational properties of governmental organizations from those of non-governmental organizations. In actuality, there is a great deal of overlap. One fundamental distinction in the United States is that government organizations have a formal authority relationship to officials whose leadership role is obtained and legitimized through democratic elections. This relationship allows them to do things that private organizations should not do, such as incarcerate people. It makes government organizations more sensitive to political pressure and, in appropriate circumstances, insulates them from certain considerations of price and efficiency.

Out of the historical and political environments from which privatization originates, three distinct streams of privatization theory have emerged. The first stream holds that the private sector is superior to the public sector. According to this view, private organizations tend to be more efficient than government organizations due to the influence of the profit motive and the bottom line. By this interpretation, the more private organizations are involved in the delivery of government services, the more efficient and cost effective those services tend to be. As public-choice theorists would argue, it is the competitive marketplace that produces goods and services efficiently. In a study conducted by the International City/County Management Association, Jeffrey Greene examines the levels of privatization in American cities. According to Greene, the basis of privatization stems from public-choice theory, whose proponents argue that "inefficiency is an inherent characteristic of municipal bureaucracies because of the incentive structures that encourage empire building and overproduction" (Greene 1996, 633). Thus, this first stream 
of thought views the private sector as having an edge over the public sector by its very nature.

A second approach to privatization was put forward by David Osborne and Ted Gaebler (1992) and was later termed "the competition prescription" by Don Kettl (1993). According to this view, the key factor that inspires efficiency is not the sector in which an organization operates, but whether it must compete for market share, functions, and resources. From this perspective, the problem of organizational waste and inefficiency occurs in both sectors and stems from habits born of monopoly.

The third stream in privatization theory is what might be termed "functional matching." Assuming the absence of monopoly, certain functions are most efficiently and effectively performed by the private sector, others by the nonprofit sector, and others by government. For example, police functions are properly governmental; nursing care is often best delivered by nonprofits; and private-sector firms often excel in construction and other manufacturing functions. In the case of police functions, the exercise of police authority might result in the loss of an individual's life or liberty. This requires a high level of clearly assignable accountability. Constitutional government and the rule of law have been specifically developed to ensure that decisions are codified, visible, and accountable. I would argue that where accountability is a critical value in the execution of a program, that program tends to be best implemented directly by government.

Nursing care provides another example for examination. While accountability is an issue in this program area, the critical day-to-day value that is of highest priority is the requirement that personnel be motivated by high levels of compassion. Nonprofits have a particular expertise in recruiting such individuals and infusing them with a strong sense of mission. Private firms may be capable of recruiting and rewarding such compassion, but only to the degree that compassion does not reduce profits, market share, and/or return on equity.

On the other hand, manufacturing and certain servicesupport functions are best performed by competing, profitseeking organizations. There is no particular sensitivity, such as individual liberty or the need for compassion, that must be taken into account during these production processes.

It is a premise of this article that the three sectors differ in ways that matter, and those differences should be taken into account when developing a program's management strategy. Understanding these sectoral distinctions is an essential step in developing a framework for deciding when and where to privatize. While it is possible to define borders between the three sectors and their characteristics, it is also clear that these boundaries are porous and there tends to be overlap among the sectors. In the context of the public and nonprofit sectors, for example, a recent theme of discussion has been a concern over a blurring of boundaries. Attention has been directed, for example, toward increased state funding of nonprofit organizations and the consequent greater susceptibility to influence, and the fact that nonprofits are increasingly drawn within the reach of state regulation (Gidron, Kramer, and Salamon 1992; Milward 1996). While it is true that there is much overlap between the sectors, it is my argument that there are still useful distinctions to be made. Such distinguishing characteristics may not provide anything resembling neat answers, but they can provide some help in deciding where and when to privatize.

With a functional-matching approach to privatization, organizations involved in formulating and implementing public policy must make the classic business make-or-buy decision: Should we do this ourselves, or should we buy it from someone else? Do we want to build and maintain distinctive competence in this area, or is this activity outside of our core functions? In making this choice, the functional-matching approach assumes that public policy must sometimes pursue values other than efficiency.

This article accepts the functional-matching approach to privatization, but then seeks to address the following central issue: What criteria does one use when matching functions to organizational sectors?

\section{Distinguishing Characteristics among the Three Sectors}

The debate about distinctions between the public and private sector is a longstanding one in the field of public administration. Seventy years ago, Wallace Sayre was fond of saying that "public and private management are fundamentally alike in all unimportant respects" (Allison 1982). Twenty years ago, Graham Allison sought to focus public management research on this issue. In a classic article in Public Administration Review, Hal Rainey, Robert Backoff, and Charles Levine (1976) identified points of consensus in academic literature on the similarities and differences between the two sectors.

In that article, Rainey and his colleagues examined (1) environmental factors, such as appropriations, as a source of resources, legal constraints, and political influences; (2) organization-environment transactions, in which government organizations tended to involve increased coerciveness due to the possibility that "customers" have no choice but to participate and only one vendor from which to buy (such as Department of Motor Vehicles); and (3) internal structures and processes, which they found in government to have more complex and possibly conflicting goals. They found government managers to possess less autonomy and decision-making authority and weaker control over subor- 
dinates. They found government to be more formal, cautious, and less innovative than the private sector. Government incentive systems seemed unreliable and relied on financial rewards less frequently.

In the 25 years since Rainey and his colleagues wrote their article, our society's focus on public management has brought some degree of change in these three areas-public organizational environment, environment-organization transactions, and internal structures and processes. Some governments have ended their monopolies on certain public services (such as garbage collection) and some have contracted out other functions. An antigovernment sentiment has dominated the political environment of publicsector organizations. We see more governments delivering public services through private firms, which are permitted to operate on a fee-for-service basis. In those instances, government obtains resources in a less coercive manner than through taxation. In the third area of analysis, internal structures and processes, we have seen significant change as government has moved to deregulate itself, while private management, paradoxically, finds itself in an increasingly regulated environment. Private firms find their human resource practices increasingly subject to litigation on grounds of bias, harassment, or other violations of civil rights and occupational health and safety rules.

Yet the relative differences between the public and private sectors remain. Government remains unique because government actions still require legal authority and will always require such legitimation. While nonprofit organizations can be defined as private organizations that are simply incorporated under a different section of the tax code, they are distinct from government and private for-profit organizations. Typically, like private for-profit organizations, a self-perpetuating board of directors governs nonprofits. However, unlike for-profit private firms, they tend to be mission driven, and their property and excess revenue belong to the organization and are not distributed to shareholders, as in private firms. Still, nonprofit employees do not necessarily take vows of poverty. These organizations may pay high salaries and bonuses and provide lavish fringe-benefit packages as well. They also distribute excess revenues to endowments, which has the effect of increasing their financial stability and the security and salaries of their employees.

\section{The Effect of Distinctions among the Three Sectors}

Given the distinguishing characteristics of public, private, and nonprofit organizations, what are the implications for a program's management strategy? Can public policy be implemented in any sector one chooses? Do these differences matter at all? To answer these questions, two fundamental questions must be addressed: Do the sectors differ in ways that affect the implementation of public programs? If they tend to differ, in what ways and under what conditions?

One place to begin this discussion is with two types of governmental functions that private organizations seem poorly suited to perform: (1) those that regulate or remove the freedom or free movement of individuals; and (2) activities that have no obvious customer with the resources to provide a profit to the organization that performs it.

\section{Police and Regulatory Functions}

In many respects, the police function is a central role for government. The irreducible purpose of government is to provide the rules and means to enforce an endwhat Hobbes termed the war of all against all (Sabine 1961, 464). Still, governments hire mercenaries, and the provision of private security forces is currently a growth industry in the United States. Additionally, private firms manage some prisons. It is certainly possible to imagine a range of police and judicial functions that private firms could be used to perform. Arguably, however, these functions are a poor match for private-sector capabilities. First, decisions to apply force and to incarcerate individuals must be the responsibility of public officials. When private parties perform these tasks, we call it assault and kidnapping. The time and labor requirements of due process are not well served by an organization concerned with productivity and efficiency. In fact, criminal and civil justice may be one area where it is clear that efficiency is not as important as justice or fairness. In the end, the pursuit of these values is not what private for-profit organizations are designed to do.

While it is possible to imagine some niche roles for the private sector in criminal justice and policing, these functions require extreme levels of public accountability and are better suited to government. A similar argument can be made with respect to regulatory functions, which are also best suited to government control. Yet there is also a role for the private sector in regulation. One example is the use of private insurance as a method of selfregulation (Cohen and Kamineiecki 1991). Insurance companies may refuse to insure against risks unless certified professionals have inspected the facilities. Building owners in New York City are one example of such self-regulation. At the beginning of the twentieth century, boiler explosions caused numerous apartment fires, prompting insurance companies to require boiler inspections as a condition of issuing insurance. Soon thereafter, boiler explosions became rare occurrences. This form of private self-regulation reduced fire losses and had the positive public outcome of saving lives. No government role was required. Owners insured their buildings out of 
enlightened self-interest, and insurance companies required safe boilers for the same reason. When interests align, government intervention becomes unnecessary.

But what if a firm decides not to take out insurance? What if the danger is not to one's own property, but to someone else's? While a firm's concern about the impact of liability law might lead it to want insurance, sometimes firms do not bother to insure or constrain risks. In the mid-1980s, for example, over one-third of the nation's underground gasoline tanks - the ones at the neighborhood gas station-were leaking. Valuable gasoline was leaking into ground water, soil, and basements all over the United States. One would have thought the companies insuring these commercial establishments against property loss and liability judgments would have insisted that the tanks not leak, but they did not-government regulation was necessary to make such leaks illegal. The Environmental Protection Agency required gas stations to carry insurance that specifically covered damage from leaking tanks, believing that insurance companies would insist that the tanks be inspected and replaced if they were leaking. While some insurance companies did insist on inspections as a precondition of issuing insurance, in other cases the price of insurance increased and many insurance companies refused to insure underground tanks. The risk was greater than the payoff. This is a clear example of a police function that the private sector was asked to take on and was unable to perform.

\section{Services without Paying Customers}

A second area in which private organizations are not well suited to perform are those with no obvious customer to provide resources to the organization that performs the work. In New York City, government delivers services to homeless individuals and families through shelters run by both the government and nonprofit contractors. While some for-profit private firms, such as Lockheed, Maximus, and America Works, have entered the business of providing welfare services, it tends to be a functional area that resists privatization. However, as cost pressures increase in government, private firms are beginning to compete in this area and are pressuring nonprofits to develop more businesslike methods of operation (Ryan 1999).

Nonprofit organizations can provide competition to government bureaucracies. They are also valued for their ability to recruit staff who are motivated by mission and do not demand high salaries. One reason that private firms are rare in social-service delivery is the need for customer subsidization by government and political sensitivity to poverty profiteering. When governments seek to privatize in this program area, they typically contract with nonprofit organizations. In Indianapolis, for ex- ample, Goodwill Industries manages a great deal of the local Welfare-to-Work program. In New York City, a relatively large, well-funded nonprofit, Homes for the Homeless, uses private-sector financial controls and management systems to deliver efficient service to homeless families. Revenues that exceed expenses are reinvested in new services or endowment, and the contracting agency does not run the risk of a scandal over "excess" profits. This provides the government with some of the advantages of privatization, but also provides the benefit of a staff that is mission driven and an organization that has a positive public image.

Some programs have both paying and nonpaying customers. In the area of education, some taxpayers do not have school age children, and some taxpayers send their children to private schools. Some public school students are children of poor people who either do not pay taxes or whose taxes do not cover the full cost of education. In March 1999, a major controversy erupted in New York City when the chancellor of the city's one-million-student public school system resisted the mayor's effort to conduct a pilot experiment with school vouchers. In the chancellor's view, public education was threatened by the potential public funding of private education.

The case of vouchers raises issues of public policy rather than issues of public management. Public education is an important civic investment that serves important public purposes. If you support the policy of universal public education, vouchers can be seen as a threat to that policy and can be opposed as bad public policy. However, in contrast to the police function of government, there is no reason that a private school cannot play the same education and socializing role as a government-run school. Private schools can be regulated to require diversity, and they are now regulated to ensure that government-imposed standards of learning are achieved. There is a benefit to competition as a method for keeping school administrations and teachers sharp and open to new ways of educating children. However, even if private schools can be made to perform some of the integration and socializing roles played by public education, they cannot perform the symbolic role of the public schools. Public education might be valued as an expression of our society's values and even as an element supporting a democratic political system. A similar policy argument has been made about the value of a universal draft requirement for military service. A professional, all-volunteer army may be a better managed and possibly more capable organization than one comprising conscripts. However, the political impact of a citizen army is its ability to increase the visibility of war and peace-a goal that might transcend the goal of managerial efficiency. 


\section{Privatization and Management Strategy}

What does this mean to the government manager who is seeking to decide whether to use government or private-sector staff to perform a function? First, it means the decision to privatize is situational and must be considered as an element of organizational strategy. A framework for making those decisions must illuminate the strategic choices at issue and the potential impacts of particular choices. John Donahue utilizes principal-agent theory to express the variables that affect the "make-or-buy" or "hire vs. contractout" decision. Under this theory, the principal enters into a contractual relationship with an agent, who is expected to carry out the actions needed to produce the outcome desired by the principal. According to this framework, there are two fundamental problems with contracting: (1) adverse selection-picking the wrong contractor, one who is not able to produce the desired outcomes; and (2) moral hazard-because the agent's behaviors cannot be observed at all times, it is possible that even a capable organization will shirk its responsibilities and divert resources to other tasks or simply to profit. According to Donahue,

The relative appeal of employing people, as opposed to contracting with them, increases (1) the more the task at hand is uncertain at the outset and prone to revision, (2) the harder it is to measure the value of production, (3) the more disruptive it is to switch agents in midstream, and (4) the more the principal knows about the best means to accomplish his task. Conversely, arms length contracts with outside suppliers are more attractive (1) the more precisely requirements can be specified in advance, (2) the more the principal cares about ends over means, (3) the more difficult it is to monitor fidelity to instructions (or the easier it is to measure results), and (4) the more readily incompetent or unfaithful agents can be replaced. (Donahue 1989, 45)

Donahue's work begins to suggest some of the issues relevant to the privatization decision. However, other issues lie outside the principal-agent framework. One is the symbolic value of a public resource for the purposes of equity, fairness, and community building. For example, while it may be expedient to privatize schools to break up a moribund and poorly performing monopoly, the socialization role played by public schools is sacrificed. A common school experience for people of all backgrounds can be of great benefit to a society that stresses merit and class mobility. Even a private school with a large scholarship program does not educate rich and poor together as a matter of right; instead, these opportunities are provided as an act of charity. One can say this is simply a case of the principal caring more about means than ends, but it is, in part, a concern for issues beyond the instrumental relationship of ends to means.
The issue is not one of interorganizational relations, but a broader set of issues that includes the way we define ourselves as a society and touches on public morality, public and governmental ethics, collective, shared sacrifice, and community building. These are concepts that are beyond the reach of principal-agent theory because the public and its institutions are both principals and agents. Tasks cannot be contracted out because doing the work and participating in decision making is part of the output and outcome of the program.

The privatization decision should be seen as situational and context laden. Some services, such as policing, are difficult for private firms to perform successfully. Other services, such as education and military service, may be better managed by private organizations, but, due to the importance of other values, should not be privatized. This leads to the conclusion that a strategic framework is useful for analyzing the privatization decision, one in which privatization is part of a broader framework that includes history and other contextual factors in an analysis that relates ends to means in designing a program. Steven Cohen and William Eimicke have observed, "A strategy attempts to delineate the resources that will be used to pay for specific activities designed to accomplish specific objectives. Strategy formulation begins with the identification of objectives and the determination of methods for reaching objectives. These objectives and activities are then scaled to fit within resource constraints. Each element of a strategy (objectives, activities and resources) is constrained by political, social, economic and environmental variables. The objectives and activities of public organizations are constrained by the formal authority provided by statute" (Cohen and Eimicke 1995, 196).

A strategic orientation requires us to relate means to ends and to ask how our goals might best be achieved given the fiscal, political, social, and economic context within which we operate. The analysis might begin with principal-agent considerations, but then should follow with an explicit consideration of the real-world context that constrains economic and all other rationalities. It must include a discussion of the purpose and goals of the community. Government programs have production functions and can be seen as having principal-agent relations, but they also have other objectives beyond task accomplishment.

\section{A Strategic Framework for Making the Privatization Decision}

A strategic framework for addressing privatization may be developed in the form of a set of questions that should be asked by government organizations faced with the decision of whether to privatize. While other questions could 
certainly be asked, the privatization-strategy formulation process would benefit from raising the following issues:

1. What are the goals of the program we are planning?

1a. Are there any political or social/cultural constraints on contracting with private for-profit firms to do this work?

1b. Are there any political or social/cultural constraints on contracting with a nonprofit organization to do this work?

1c. To what degree might this goal and its associated activities be considered a mission or an aspect of a mission?

1d. Can the goal of this program be used to motivate staff? If so, how?

2. What are the tasks that must be performed to achieve the program's goals?

2a. Who designs these tasks?

2b. Who is permitted to provide input in program and task design?

3. Does the government currently have the capacity to perform these tasks?

3a. Are there other organizations with more experience in performing these tasks?

3 b. Which organizations have demonstrated the most efficiency in performing these tasks?

3c. How well developed is the technology needed to implement these tasks?

$3 \mathrm{~d}$. How risky is the technology used to perform these tasks?

4. How measurable are the outputs and outcomes of the activities we are seeking to undertake?

4a. Is data collection feasible and simple?

4b. Can data be verified? How easy is it for those carrying out these activities to lie about work performed, the outputs produced, and the impacts obtained?

5. How capital intensive is the activity?

5a. Are the costs and availability of capital issues?

5b. If so, are private or public sources of capital more or less available and expensive?

6. How much risk is involved in performing this activity?

$6 \mathrm{a}$. What risks are involved?

6b. Could private providers obtain insurance to cover personal risks and third-party liability?

7. What is the impact if the activity is performed poorly?

7a. Are the impacts irreversible? At what price might they be reversed?

7b. What is the potential political, social, and economic impact of failure?

8. Is there a competitive market for the activity we are considering privatizing?

8a. How deep is the market? Does it operate in this locality? 8b. Would privatizing this function help create such a market?

$8 \mathrm{c}$. What might be done to stimulate such a market?

$8 \mathrm{~d}$. Are there efficiency gains that might be obtained through privatization?

9. What is the output expected from this activity?

9a. Can it be measured?

9b. How difficult is it to measure and report the accomplishment of this output?

10. What is the outcome or impact expected from this activity?

10a. Can it be measured?

10b. How difficult is it to measure and report these impacts?

The following analysis of a privatization issue that might be faced in New York City's homeless program provides an example of how this framework might be applied.

\section{The Case of Privatizing Homeless Services in New York City}

New York City's Department of Homeless Services is the agency in the city responsible for providing housing and other social services to homeless individuals and families. The Department is divided into two program divisions, Adult Services and Family Services. Adult Services provides services to homeless single adults, managing 44 shelters that provide beds to about 7,000 people. In 1998, 36 of these facilities were operated by nonprofit organizations and eight were run by the city. The division also manages contracts with nine nonprofit outreach centers and six nonprofit outreach teams. The Division of Family Services manages or operates 68 family shelters (mostly run by nonprofits), 10 hotels, five specialized residences, and three reception centers. Entry into the entire family services system takes place in a single location in the Bronx, at the government-run Emergency Assistance Unit.

Homelessness is a very visible and emotional issue in New York City. During cold weather, people without shelter are in danger of dying from exposure to cold and illness. Housing is expensive, and the low end of the housing market is underserved. Due to living and transportation patterns, even wealthy New Yorkers cannot avoid seeing the homeless, and the media continues to cover the issue extensively.

Most of the homeless services provided by New York City have been successfully privatized and could be completely privatized if the government chose to do so. The one service that remains completely government-run is intake for family services. The following analysis examines the issue of privatizing the city's Emergency Assistance Unit. It addresses the relevant questions from among those listed above. 
The goal of the Family Services Division is to ensure that homeless families have shelter without creating longterm dependency on public resources to provide that shelter. The goal of the Emergency Assistance Unit, the division's intake center, is to screen applicants and then send them to an appropriate and available facility. The administration of the intake function necessarily requires the refusal of service. It is likely that any refusals would still require a government-staffed appeal process. If a family were rejected and subsequently harmed and was highlighted by the local media, the political reaction might be intense. However, while an arms-length contractor relationship might not insulate public officials from accountability, if a contract were properly drawn, it might provide a mechanism for penalizing or terminating a contractor who performed poorly.

The difficulty for any organization undertaking this intake function is determining when to refuse service. While a nonprofit organization could inspire people around the mission of helping the homeless, it would be difficult to get such an organization to be tough-minded about refusals. On the other hand, a for-profit private firm might be better at doing the work, but it might have a tin ear toward the politics of refusing aid to families claiming to be homeless.

The tasks involved in homeless intake are fairly straightforward: The central task is to determine eligibility for services and assign those who are eligible to particular shelters. While law determines the criteria, the staff of the Emergency Assistance Unit must design the specific tasks required to apply those criteria. Presumably, some of the service providers must be involved in the process, at a minimum providing data on current capacity. One problem with the current Emergency Assistance Unit is that homeless families waiting for placement or arriving too late in the day to obtain placement have taken to sleeping on the floor of the unit's offices. Despite these problems, government workers in the Department of Homeless Services currently have the most experience to perform these tasks. However, there is no reason that a competent private organization could not quickly learn these fairly routine tasks and do this work. There is no technological expertise needed to perform these tasks. Knowledge of some fairly simple standard operating procedures and modest security presence are all that are needed to safely undertake this work.

The outputs and outcomes of this work are also fairly straightforward: How many families come in for service? How many are referred? How many are rejected? What is more difficult is measuring the number of people who are discouraged from coming in for service and end up sleeping on the street. Given the large network of nonprofit providers, it is difficult to know how many families find permanent housing and leave the system. While it is fairly easy to lie in reporting these data, it is also very easy to audit and spot check the accuracy of reporting from a single intake unit.

The capital needs of the intake function are quite minor, while the shelters themselves can be large facilities requiring substantial capital for construction and renovation. The intake center can be a rented office or, if contracted, could be located in a city building, as it is now. The on-site risks are fairly routine, and the only liability concern might come if a court decided to assign liability to the organization if it denied benefits and the claimant were injured.

The impact of performing this intake service poorly is significant. If eligibility is made too easy, the shelter system could be overwhelmed. If eligibility is administered too stringently, families could suffer from exposure, hunger, and other injury. Moreover, if a pattern of poor decision making were uncovered and exposed by the media, it could damage the political standing of the administration supervising the contractor. While most mistakes could be corrected over time, the death of any rejected applicant would obviously be irreversible.

There are a large number of nonprofit organizations in New York City with the capacity to perform these tasks. The private for-profit market for performing such a service is difficult to measure. It is unlikely that a large national firm or a strong local market could be developed from privatizing a single intake facility. However, if a request for proposal were carefully constructed or linked to the provision of homeless services, it might be possible to attract several large nonprofit organizations into a competitive-bidding process.

Would it be worth it? Are there efficiency gains that might be obtained through privatization? Could a nonprofit vendor do a better job of delivering this service than government? Certainly overhead and administrative costs could be lowered by contracting out. A detailed analysis of labor costs and productivity would be needed to determine if operating costs could be reduced. The goal of this activity is to ensure that families with no place to live are given temporary shelter. Other programs are responsible for permanent housing and dealing with employment issues. Important measures would include the number of families processed, number housed, and number refused. These outputs can be easily measured, and the number of families housed can be verified when cross-checked against actual housing sign-ins at family shelters. While some families might never make it to the shelter, over time the noshow rate should be measurable and possibly consistent.

The impact of this service is that families in true need of shelter would receive housing and those not in need would be denied housing. However, a negative impact of this service would occur if people in true need were 
denied housing and ended up with no place to live-a very difficult impact to measure. Often homeless families have been evicted from sharing arrangements with families and friends, and it is difficult for them to know whether they will have a place to stay if they are denied help by the government.

Having completed this cursory strategic analysis, what advice would I give the New York City Department of Homeless Services? If the cost analysis indicates that a contractor could run the Emergency Assistance Unit for less money than the government, the function could successfully be contracted to a large nonprofit organization. To be successful, the Department of Homeless Services would need to develop a performance-measurement system and a strong audit and evaluation unit. It would also make sense to have a government employee on hand to review all service refusals and adjudicate on-the-spot appeals of refusals. In my view, the greatest risk to government comes from harm resulting from refusals. If a problem of too few refusals developed, it could be remedied gradually with new procedures and training.

\section{Conclusion: Deciding to Privatize}

It is critical that government managers resist bias and easy assumptions in making the outsourcing decision. Data should be collected about operations, and the political and social context of the program area must be well understood before making the "make-or-buy decision." The approach discussed here argues that, despite the difficulty in precisely delineating distinctions between the public, nonprofit, and private sectors, such distinctions can be made at the operational level. They represent tendencies rather than absolute distinctions, and they should be factored into the decision to privatize a government function.

Beyond the specific distinctions among the three sectors, I have argued for a strategic approach to privatization. Under this approach, decision makers should consider organizational traits to be only one of a much broader set of political, economic, social, technical, and ethical issues that should be considered when making the "makeor-buy" decision.

\section{Acknowledgments}

The author gratefully acknowledges the research assistance of Lynette Munez, John Pfeiffer, Megan Watkins, and Meredith Younger, all graduate students at Columbia University's School of International and Public Affairs when they assisted on this article.

\section{References}

Allison, Graham Jr. 1982. Public and Private Management: Are They Fundamentally Alike in All Unimportant Respects? In Current Issues in Public Administration, 2nd ed., edited by F. Lane, 13-33. New York: St. Martin's Press.

Cohen, Steven, and William Eimicke. 1995. The New Effective Public Manager. San Francisco, CA: Jossey-Bass. Bass.

Cohen, Steven, and Sheldon Kamineiecki. 1991. Environmental Regulation through Strategic Planning. Boulder, CO: Westview Press.

Donahue, John D. 1989. The Privatization Decision: Public Ends, Private Means. New York: Basic Books.

Gidron, Benjamin, Ralph M. Kramer, and Lester M. Salamon. 1992. Government and the Third Sector in Comparative Perspective: Allies or Adversaries. In Government and the Third Sector: Emerging Relationships in Welfare States, edited by Benjamin Gidron, Ralph M. Kramer, and Lester M. Salamon, 1-30. San Francisco, CA: Jossey-Bass.

Gilmour, Robert S., and Laura S. Jensen. 1998. Reinventing Government Accountability: Public Functions, Privatization, and the Meaning of "State Action." Public Administration Review 58(3): 247-57.

Greene, Jeffery D. 1996. How Much Privatization: A Research Note Examining the Use of Privatization by Cities in 1982 and 1992. Policy Studies Journal 24(Winter): 632-40.

Kettl, Donald F. 1993. Sharing Power: Public Governance and Private Markets. Washington, DC: Brookings Institution.

Milward, H. Brinton. 1996. The Changing Character of the Public Sector. In Handbook of Public Administration, 2nd ed., edited by James L. Perry, 77-91. San Francisco, CA: JosseyBass.

Osborne, David, and Ted Gaebler. 1992. Reinventing Government: How the Entrepreneurial Spirit is Transforming the Public Sector. Reading, MA: Addison-Wesley.

Rainey, Hal, Robert Backoff, and Charles Levine. 1976. Comparing Public and Private Organizations. Public Administration Review 36(2): 236-37.

Ryan, William P. 1999. The New Landscape for Nonprofits. Harvard Business Review 77: 127-36.

Sabine, George H. 1961. A History of Political Theory, Third Edition. New York: Holt, Rinehart, and Winston.

Savas, Emmanuel S. 1989. Privatization. Chatham, NJ: Chatham House Publishers. 